\title{
Discovery of new methylation markers to improve screening for cervical intraepithelial neoplasia grade $2 / 3$
}

\author{
A. Boers ${ }^{1}$, R. Wang ${ }^{1}$, R. W. van Leeuwen ${ }^{1}$, H. G. Klip', G. H. de Bock², H. Hollema', W. van Criekinge ${ }^{4}$, T. de Meyer ${ }^{4}$,
} S. Denil ${ }^{4}$, A. G J. van der Zee ${ }^{1}$, E. Schuuring ${ }^{3+}$ and G. B. A. Wisman ${ }^{1 *+}$

\begin{abstract}
Background: Assessment of DNA promoter methylation markers in cervical scrapings for the detection of cervical intraepithelial neoplasia (CIN) and cervical cancer is feasible, but finding methylation markers with both high sensitivity as well as high specificity remains a challenge. In this study, we aimed to identify new methylation markers for the detection of high-grade CIN (CIN2/3 or worse, CIN2+) by using innovative genome-wide methylation analysis (MethylCap-seq). We focused on diagnostic performance of methylation markers with high sensitivity and high specificity considering any methylation level as positive.

Results: MethylCap-seq of normal cervices and CIN2/3 revealed 176 differentially methylated regions (DMRs) comprising 164 genes. After verification and validation of the 15 best discriminating genes with methylationspecific PCR (MSP), 9 genes showed significant differential methylation in an independent cohort of normal cervices versus $\mathrm{CIN} 2 / 3$ lesions $(p<0.05)$. For further diagnostic evaluation, these 9 markers were tested with quantitative MSP (QMSP) in cervical scrapings from 2 cohorts: (1) cervical carcinoma versus healthy controls and (2) patients referred from population-based screening with an abnormal Pap smear in whom also HPV status was determined. Methylation levels of $8 / 9$ genes were significantly higher in carcinoma compared to normal scrapings. For all 8 genes, methylation levels increased with the severity of the underlying histological lesion in scrapings from patients referred with an abnormal Pap smear. In addition, the diagnostic performance was investigated, using these 8 new genes and 4 genes (previously identified by our group: C13ORF18, JAM3, EPB41L3, and TERT). In a triage setting (after a positive Pap smear), sensitivity for CIN2+ of the best combination of genes (C13ORF18/JAM3/ANKRD18CP) (74\%) was comparable to hrHPV testing (79\%), while specificity was significantly higher (76\% versus $42 \%, p \leq 0.05)$. In addition, in hrHPV-positive scrapings, sensitivity and specificity for CIN2+ of this best-performing combination was comparable to the population referred with abnormal Pap smear.

(Continued on next page)
\end{abstract}

\footnotetext{
*Correspondence: g.b.a.wisman@umcg.nl

${ }^{\dagger}$ Equal contributors

'Department of Gynecologic Oncology, internal postal code DA13, Cancer

Reserch Center Groningen, University of Groningen, University Medical

Center Groningen, PO box 30.001, 9700 RB Groningen, The Netherlands

Full list of author information is available at the end of the article
} 
(Continued from previous page)

Conclusions: We identified new CIN2/3-specific methylation markers using genome-wide DNA methylation analysis. The diagnostic performance of our new methylation panel shows higher specificity, which should result in prevention of unnecessary colposcopies for women referred with abnormal cytology. In addition, these newly found markers might be applied as a triage test in hrHPV-positive women from population-based screening. The next step before implementation in primary screening programs will be validation in population-based cohorts.

Keywords: Cervical cancer screening, Cervical precancerous lesions, Human papillomavirus (HPV), Cervical scraping, MethylCap-seq, DNA methylation, Quantitative methylation-specific PCR (QMSP)

\section{Background}

Cervical cancer is characterized by a well-defined premalignant phase, cervical intraepithelial neoplasia (CIN). Identification of these high-grade CIN (HSIL) lesions by population-based screening programs and their subsequent treatment has led to a significant reduction of the incidence and mortality of cervical cancer $[1,2]$. Cytology-based testing of cervical smears is the most widely used cervical cancer screening method but is not ideal, as the sensitivity for detection of CIN2 and higher (CIN2+) is only $55 \%[3-5,51]$. Cervical carcinogenesis is highly associated with high-risk human papillomavirus (hrHPV) [6]. Large randomized controlled trials have shown that the sensitivity of hrHPV testing is significantly higher than cytology testing [4, 7-10]. Based on these data, starting in 2016, the Netherlands is one of the first countries to implement hrHPV testing as primary cervical cancer population-based screening. However, the specificity of hrHPV testing, especially in a young screening population, is relatively low $[3,11-13]$, which may lead to unnecessary referrals to the gynecologist, anxiety in the false-positive women, and higher costs for the health-care system. Finally, in the near future, the prevalence of CIN and cervical cancer will probably decrease in countries that have introduced primary prevention with hrHPV vaccination. With this decrease in prevalence, the positive predictive value of the current screening tests will by definition decrease [14]. Therefore, other objective biomarkers with both high sensitivity as well as high specificity are needed as new screening tools for cervical cancer.

Different DNA methylation patterns in normal versus (pre)malignant lesions represent excellent targets for diagnostic approaches based on methylation-specific PCR (MSP). Promoter hypermethylation of tumor suppressor genes is an early event in cervical carcinogenesis and consequently hypermethylation analysis can be especially relevant for the early detection of cervical neoplasia [15-17]. Assessment of methylation markers in cervical scrapings for the detection of CIN and cervical cancer is feasible [17-23], but obtaining methylation markers with both high sensitivity as well as high specificity remains a challenge. Through the years, gradually more sophisticated approaches have been developed to identify new methylation markers on a genomewide scale [24]. Amidst comparable studies from other groups, we have previously reported our experience with pharmacological unmasking of the promoter region combined with re-expression as analyzed by microarrays, high-throughput quantitative methylation-specific PCR (QMSP) on an OpenArray platform, and methyl-DNA immunoprecipitation followed by microarray analysis (MeDIP), resulting in the discovery and validation of the genes C13ORF18, JAM3, EPB41L3, and TERT [21, 22, 25]. The diagnostic performance of these genes showed sensitivities for detecting $\mathrm{CIN} 2+$ in a hrHPV-positive population between 43 and $71 \%$ and specificities between 89 and $100 \%$ [21]. However, most strategies (including ours) for discovering new methylation markers so far were based on the difference between cancer and normal tissue resulting in markers with high sensitivity for carcinoma, but with too low sensitivity for detecting CIN2/3 lesions $[21,22,26,27]$. New and more specific innovative genome-wide methylation analysis of DNA from CIN2/3 lesions versus normal cervical tissue should result in (new) CIN2/3-sensitive and -specific methylation markers. MethylCap-seq uses methyl-binding domain (MBD) proteins to specifically enrich for methylated DNA, followed by sequencing $[28,29]$. The higher affinity of the MBD complex for double-stranded CpG-methylated DNA results in a higher enrichment for methylated DNA sequences as compared to MeDIP analysis. Using nextgeneration sequencing, a unique methylome of each sample will be generated (MethylCap-seq). After identification of novel methylation markers for (pre)malignant cervical neoplasia through this approach, validation and diagnostic evaluation of these newly found markers can be performed.

The aim of the present study was to identify new methylation markers that can differentiate between normal cervices and CIN2/3 lesions using MethylCap-seq with high specificity and high sensitivity. To validate the diagnostic performance of the newly found methylation markers considering any methylation level as positive, 
cervical scrapings will be tested as triage test after either primary cytology or primary hrHPV analysis using QMSP. Because for most of the reported markers in literature a cut-off value was set above a certain methylation level in order to obtain high specificity, we will preferentially select differentially methylated markers without setting a cut-off allowing a test that should be more objective and easy to interpret.

\section{Results}

\section{Identification of differential methylated genes by} MethylCap-sequencing

To identify new CIN2 or higher (CIN2+) specific methylation markers, we applied the strategy as shown in Fig. 1.

In short, genome-wide MethylCap-seq was used to compare the DNA methylation profiles of CIN2/3 dysplastic cervical cells with normal cervical cells to identify CIN2/3-specific differential methylated regions (DMRs). After applying our selection criteria (see "Methods" section for detailed description), 176 DMRs comprising 164 genes remained. The list of DMRs is shown in Additional file 1: Table S1, ranked on the sum of unmethylated normal samples and methylated CIN2/3 samples. The range of reads obtained for all these 176 DMRs of all samples considered methylation positive was from 3-17 reads with a median of 4 reads (data not shown).

\section{Verification and validation of the top 15 differentially methylated genes}

To verify the MethylCap-seq data, the top 15, out of the 163 identified genes, were selected. Methylation-specific PCR (MSP) primers were designed and could be optimized for 14 out of the 15 genes. Verification of the selected 14 genes showed for 11 genes a significant correlation between the MSP band intensity and the amount of reads from the MethylCap-seq data. One gene $(P C D H 17)$ showed high methylation levels in leukocytes and was excluded for further validation in order to prevent false-positive methylation signals in samples of healthy women. The remaining 10 genes passed verification and continued to the subsequent validation step. Table 1 shows an overview of which genes continued through the different stages of validation.

The second validation step was performed by MSP on DNA isolated from FFPE tissue of an independent, randomly selected new patient cohort that consisted of 13 cervical cancers, 19 HSIL lesions (8 CIN2, 8 CIN3, and 3 adCIS) and 17 normal cervices. Out of the 10 genes analyzed, 9 were not methylated in almost all normal samples, significant differential methylation between normal versus HSIL lesions and again little to no methylation in the leukocytes $(p<0.05)$ (Table 2). These 9 genes (ZSCAN1, ST6GALNAC5, ANKRD18CP, PAX2, CDH6, GFRA1, GATA4, KCNIP4, and LHX8) were

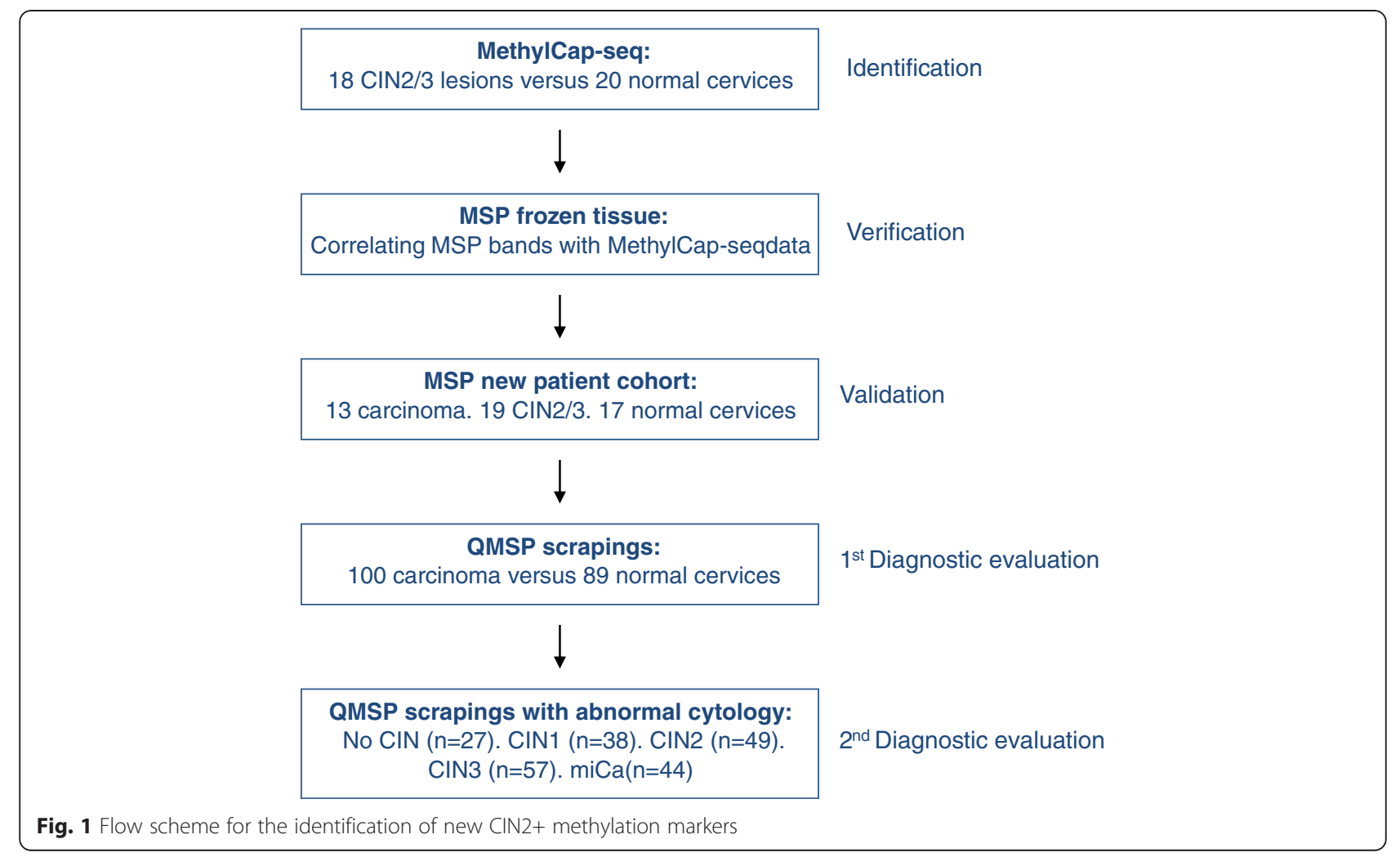


Table 1 Verification, validation, and diagnostic evaluation of the highest ranking top 15 genes

\begin{tabular}{|c|c|c|c|c|c|c|}
\hline Rank & Gene & Optimized & Verification & Validation & 1st diagnostic evaluation & 2nd diagnostic evaluation \\
\hline 1 & ZSCAN1 & Yes & Yes & Yes & Yes & Yes \\
\hline 2 & PCDH17 & Yes & $\mathrm{No}^{\mathrm{a}}$ & & & \\
\hline 3 & ST6GALNAC5 & Yes & Yes & Yes & Yes & Yes \\
\hline 4 & CLIC6 & Yes & No & & & \\
\hline 5 & RP11-89 K21.1.1 & Yes & No & & & \\
\hline 6 & ANKRD18CP & Yes & Yes & Yes & Yes & Yes \\
\hline 7 & $P A X 2^{b}$ & Yes & Yes & Yes & No & \\
\hline 8 & $\mathrm{CDH} 6$ & Yes & Yes & Yes & Yes & Yes \\
\hline 9 & GFRA1 & Yes & Yes & Yes & Yes & Yes \\
\hline 10 & $\operatorname{IRX} 1$ & Yes & No & & & \\
\hline 11 & POU4F3 & Yes & Yes & $\mathrm{No}^{\mathrm{a}}$ & & \\
\hline 12 & GATA4 & Yes & Yes & Yes & Yes & Yes \\
\hline 13 & MKX & No & & & & \\
\hline 14 & $P A X 2^{b}$ & Yes & No & & & \\
\hline 15 & KCNIP4 & Yes & Yes & Yes & Yes & Yes \\
\hline 16 & LHX8 & Yes & Yes & Yes & Yes & Yes \\
\hline
\end{tabular}

axcluded due to high methylation in leukocytes

${ }^{\mathrm{b}}$ Same gene, different region

selected for further diagnostic evaluation in cervical scrapings (Table 2).

\section{Diagnostic evaluation by QMSP for normal versus cancer scrapings}

To evaluate the diagnostic value of the new methylation markers (Table 2), cervical scrapings from two cohorts of patients were used: (1) normal versus carcinoma scrapings and (2) scrapings from patients referred from population-based screening with an abnormal Pap smear ( $\geq$ pap2).

Table 2 Methylation positivity in an external cohort of FFPE samples to validate results of high methylation in CIN2+ lesions and no methylation in normal cervices of the newly found methylation markers

\begin{tabular}{llllll}
\hline Gene & Normal & CIN2 & CIN3 & adCIS & Carcinoma \\
\hline ZSCAN1 & $4 / 16$ & $8 / 8$ & $7 / 8$ & $3 / 3$ & $12 / 13$ \\
ST6GALNAC5 & $0 / 16$ & $1 / 6$ & $4 / 8$ & $2 / 3$ & $9 / 12$ \\
ANKRD18CP & $0 / 16$ & $1 / 8$ & $1 / 7$ & $2 / 3$ & $6 / 12$ \\
PAX2 & $1 / 14$ & $6 / 8$ & $7 / 8$ & $3 / 3$ & $5 / 13$ \\
CDH6 & $1 / 15$ & $3 / 8$ & $4 / 8$ & $3 / 3$ & $7 / 13$ \\
GFRA1 & $0 / 12$ & $2 / 8$ & $3 / 8$ & $2 / 3$ & $10 / 12$ \\
POU4F3 & $2 / 14$ & $6 / 7$ & $3 / 7$ & $3 / 3$ & $11 / 12$ \\
GATA4 & $0 / 17$ & $3 / 8$ & $2 / 7$ & $3 / 3$ & $10 / 13$ \\
KCNIP4 & $0 / 17$ & $6 / 8$ & $5 / 8$ & $3 / 3$ & $10 / 12$ \\
LHX8 $^{\text {a }}$ & $1 / 16$ & $3 / 8$ & $4 / 8$ & $3 / 3$ & $7 / 13$ \\
\hline
\end{tabular}

${ }^{a}$ Excluded due to high methylation in leukocytes
In cohort 1 , cervical scrapings of 100 randomly selected cervical carcinoma patients and of 89 patients with histologically confirmed normal cervices were used. QMSP analysis showed that the relative levels of DNA methylation were higher in the carcinoma scrapings compared to the normal scrapings for 8 out of the 9 selected genes $(p<0.001)$ (Fig. 2). The area under the curve (AUC) for methylation ratio in cervical carcinoma revealed for 8 genes an AUC $>0.91$ (Fig. 3). Because of an AUC of 0.59, PAX2 was excluded from further analysis.

\section{Diagnostic evaluation by QMSP for normal/LSIL versus HSIL scrapings}

In cohort 2, scrapings of 215 consecutive patients referred from population-based screening with an abnormal Pap smear were used. The 8 genes that showed differential methylation in the normal versus the cancer scrapings were subsequently tested in this cohort. Methylation levels and frequencies for all 8 genes analyzed (ZSCAN1, ST6GALNAC5, ANKRD18CP, CDH6, GFRA1, GATA4, KCNIP4, and LHX8) increased with the severity of the underlying histological lesion $(p<0.001)$ (Fig. 4 and Table 3).

Considering all detected methylation as positive to achieve higher sensitivity and/or specificity, genes ZSCAN1, ST6GALNAC5, and KCNIP4 reached high sensitivity $(\geq 90 \%)$ for detection of CIN2+ lesions, while for CDH6, GATA4 and LHX8 sensitivity for CIN2+ was between 73 and $84 \%$ (Table 4). For ANKRD18CP and 


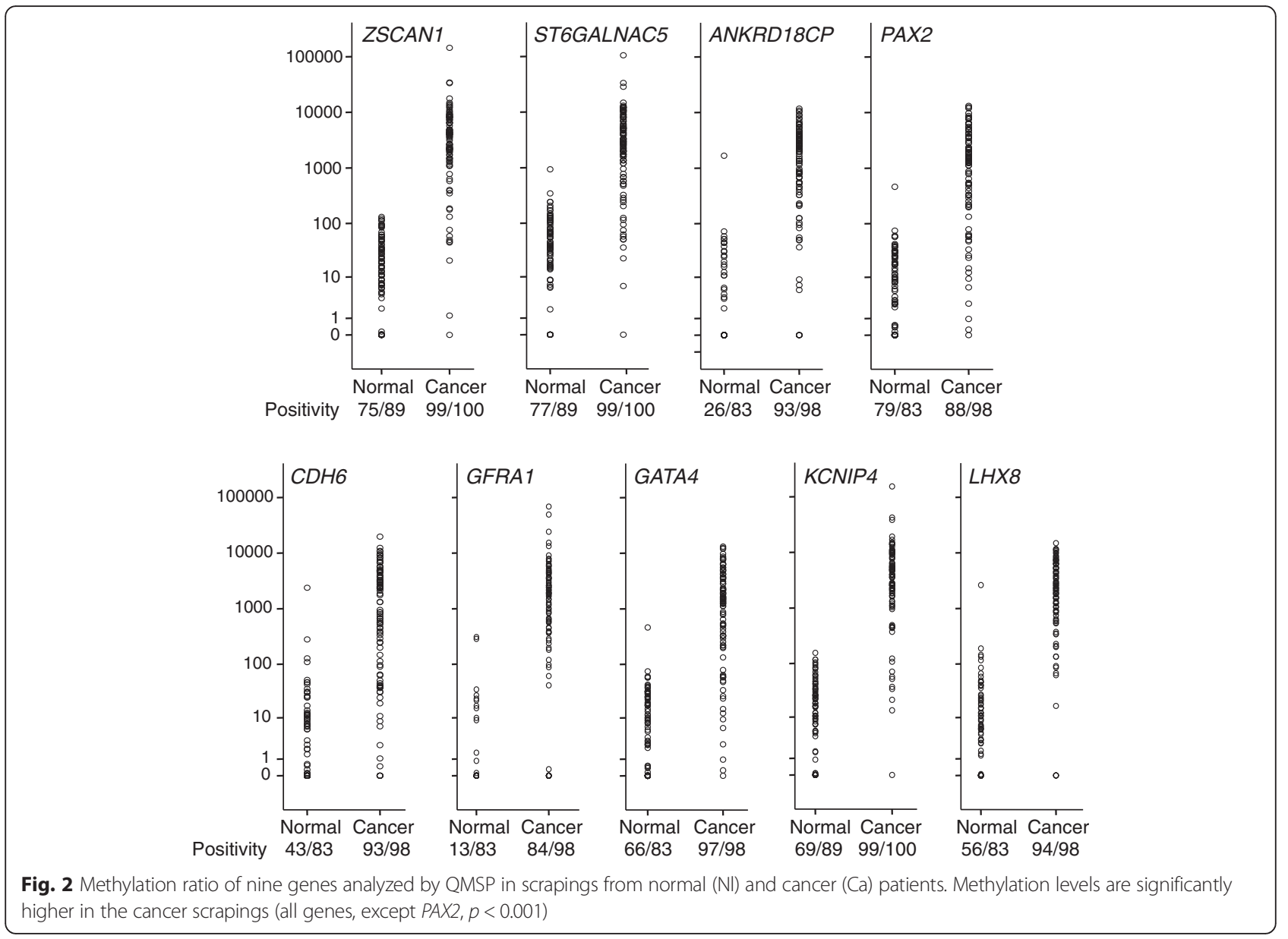

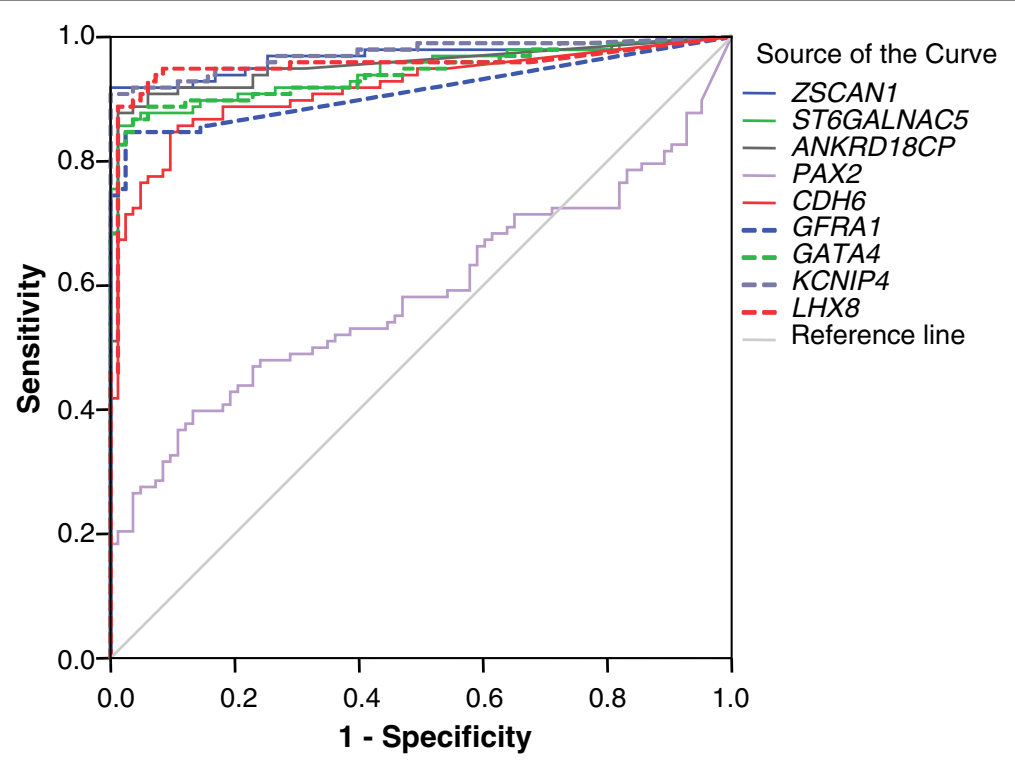

Fig. $3 \mathrm{ROC}$ analysis of methylation ratio per gene 


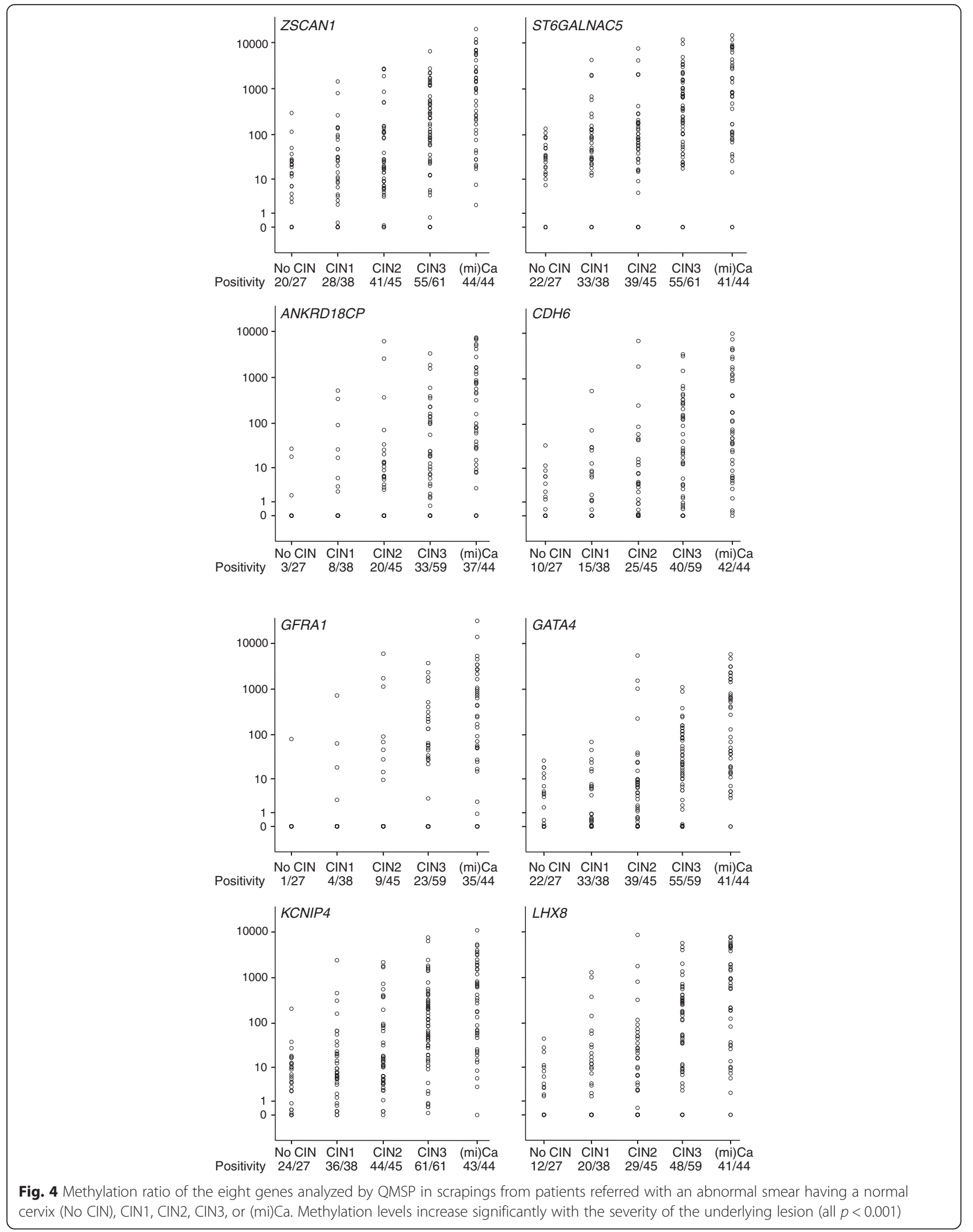


Table 3 Cytology according to the Papanicolaou system (Bethesda system) per histological subgroup. Methylation and HPV positivity of the 8 new methylation markers and 4 known markers tested with QMSP in cervical scrapings from patients with CIN0, CIN1, CIN2, CIN3, and (mi)Ca $(n=215)$

\begin{tabular}{|c|c|c|c|c|c|}
\hline Cytology & CINO & CIN 1 & CIN2 & CIN3 & miCa \\
\hline Pap2 (ASCUS) & 9/27 (33\%) & $9 / 38(24 \%)$ & $2 / 45(4 \%)$ & 0 & 0 \\
\hline Pap3A (LSIL) & 18/27 (66 \%) & 27/38 (71 \%) & $36 / 45(80 \%)$ & 18/61 (30 \%) & $5 / 44(11 \%)$ \\
\hline Pap3B (HSIL) & 0 & $2 / 38(5 \%)$ & 6/45 (13\%) & 33/61 (54 \%) & 27/44 (61 \%) \\
\hline Pap4 (HSIL) & 0 & 0 & $1 / 45(2 \%)$ & 10/61 (16 \%) & 8/44 (18 \%) \\
\hline Pap5 (miCa) & 0 & 0 & 0 & 0 & $3 / 44(7 \%)$ \\
\hline Unknown & 0 & 0 & 0 & 0 & $1 / 44(2 \%)$ \\
\hline \multicolumn{6}{|l|}{ New genes } \\
\hline ZSCAN1 & 20/27 (74 \%) & 28/38 (74 \%) & 41/45 (91\%) & 55/61 (90 \%) & 44/44 (100\%) \\
\hline ST6GALNAC5 & $22 / 27$ (82 \%) & 33/38 (87 \%) & $39 / 45$ (84 \%) & 56/61 (92 \%) & 41/44 (93\%) \\
\hline ANKRD18CP & $3 / 26(12 \%)$ & $8 / 36(22 \%)$ & 20/45 (44 \%) & $33 / 59(56 \%)$ & $37 / 43(86 \%)$ \\
\hline $\mathrm{CDH} 6$ & 10/26 (39 \%) & 15/36 (42 \%) & 25/45 (56 \%) & 40/59 (68 \%) & 42/43 (98\%) \\
\hline GFRA1 & $1 / 26$ (4 \%) & 4/36 (11\%) & 9/45 (20\%) & 23/59 (39 \%) & $35 / 43(81 \%)$ \\
\hline GATA4 & $14 / 26$ (54 \%) & $21 / 36$ (58 \%) & $35 / 45(78 \%)$ & 47/59 (80\%) & 41/43 (95\%) \\
\hline KCNIP4 & 24/27 (89 \%) & $36 / 38$ (95 \%) & 44/45 (98\%) & $61 / 61(100 \%)$ & $43 / 44(98 \%)$ \\
\hline LHX8 & 12/26 (46 \%) & 20/36 (56 \%) & 29/45 (64\%) & 48/59 (81\%) & 41/43 (95\%) \\
\hline \multicolumn{6}{|l|}{ Known genes } \\
\hline C13ORF18 & 2/27 (7 \%) & 1/38 (3 \%) & 9/45 (20\%) & 24/61 (39 \%) & 27/44 (61 \%) \\
\hline JAM3 & $3 / 27$ (11 \%) & $3 / 38(8 \%)$ & $18 / 45(40 \%)$ & 39/61 (64 \%) & $37 / 44(84 \%)$ \\
\hline EPB41L3 & 2/27 (7 \%) & 12/38 (32 \%) & 18/45 (40\%) & 44/61 (72 \%) & 41/44 (93\%) \\
\hline TERT & 13/27 (48 \%) & 22/38 (58 \%) & 29/45 (64\%) & 51/61 (84 \%) & 43/44 (98 \%) \\
\hline \multicolumn{6}{|l|}{ HPV test } \\
\hline hrHPV & $12 / 26(46 \%)$ & $24 / 36$ (67 \%) & $36 / 45(80 \%)$ & 49/59 (83\%) & $31 / 43(72 \%)$ \\
\hline
\end{tabular}

Table 4 Sensitivity and specificity results for CIN2+ and CIN3+ in cervical scrapings from patients referred from population-based screening with an abnormal Pap smear $(n=215)$

\begin{tabular}{|c|c|c|c|c|}
\hline Gene & Sensitivity CIN2+ & Specificity CIN2+ & Sensitivity CIN3+ & Specificity CIN3+ \\
\hline \multicolumn{5}{|l|}{ New genes } \\
\hline ZSCAN1 & $93 \%$ & $26 \%$ & $94 \%$ & $19 \%$ \\
\hline ST6GALNAC5 & $90 \%$ & $15 \%$ & $92 \%$ & $16 \%$ \\
\hline ANKRD18CP & $61 \%$ & $82 \%$ & $69 \%$ & $71 \%$ \\
\hline $\mathrm{CDH} 6$ & $73 \%$ & $60 \%$ & $80 \%$ & $53 \%$ \\
\hline GFRA1 & $46 \%$ & $92 \%$ & $57 \%$ & $87 \%$ \\
\hline GATA4 & $84 \%$ & $44 \%$ & $87 \%$ & $35 \%$ \\
\hline KCNIP4 & $99 \%$ & $8 \%$ & $99 \%$ & $6 \%$ \\
\hline LHX8 & $80 \%$ & $40 \%$ & $87 \%$ & $43 \%$ \\
\hline \multicolumn{5}{|l|}{ Known genes } \\
\hline C13ORF18 & $40 \%$ & $95 \%$ & $49 \%$ & $89 \%$ \\
\hline EPB41L3 & $69 \%$ & $79 \%$ & $81 \%$ & $71 \%$ \\
\hline JAM3 & $63 \%$ & $91 \%$ & $72 \%$ & $78 \%$ \\
\hline TERT & $82 \%$ & $46 \%$ & $90 \%$ & $42 \%$ \\
\hline \multicolumn{5}{|l|}{ HPV test } \\
\hline hrHPV & $79 \%$ & $42 \%$ & $78 \%$ & $33 \%$ \\
\hline
\end{tabular}


GFRA1, sensitivity for CIN2+ was between 46 and $61 \%$, and these genes showed especially high specificity (82$92 \%)$. In our analysis, we also included the 4 genes from our previously reported 4-gene panel (C13ORF18, JAM3, EPB41L3, and TERT) to compare sensitivity and specificity of these known genes with the newly identified methylation markers. The gene C13ORF18 showed reproducible results as described previously [21] with high specificity (95\%) and relatively low sensitivity for CIN2+ of $40 \%$. JAM3 and EPB41L3 showed sensitivities for CIN2+ between 63 and $69 \%$ and specificities between 79 and $91 \%$. The gene TERT was previously described with high specificity, but this result could not be reproduced since specificity was only $46 \%$ in our present analysis, while sensitivity for CIN2+ lesions was $82 \%$.

\section{hrHPV status and triage testing}

HrHPV testing was performed on the patient group referred with abnormal cytology at population-based screening. In 152/209 (73 \%) samples, hrHPV could be detected; as for 6 out of 215 patients, insufficient material was available to perform HPV testing. Table 3 shows hrHPV status in relation to underlying histological diagnosis. HrHPV was present in 12/26 (46\%) patients without CIN lesion, 24/36 (67 \%) CIN1 patients, 36/45 (80 \%) CIN2 patients, 49/59 (83 \%) CIN3 patients, and $31 / 43$ (72 \%) patients with micro-invasive cancer (miCa). The sensitivity of hrHPV testing for CIN2+ was $79 \%$ with a specificity of $42 \%$. When comparing the sensitivity and specificity of hrHPV testing versus methylation marker testing, the genes CDH6, GATA4, and LHX8 showed comparable sensitivity and specificity results to hrHPV testing with sensitivity for CIN2+ between 73 and $84 \%$ and specificity between 40 and $60 \%$ (Table 4 ).

Table 5 shows sensitivity and specificity for CIN2+ and CIN3+ in scrapings of hrHPV-positive women $(n=152)$, which were comparable to the results for the whole group, as shown in Table 4. The genes ZSCAN1, ST6GALNAC5, and KCNIP4 again showed high sensitivity ( $\geq 92 \%$ ) for the detection of CIN2+, while for $C D H 6$, GATA4, EPB41L3, TERT, and ZSCAN16, sensitivity for CIN2+ was between 72 and $85 \%$. For ANKRD18CP, JAM3, C13ORF18, and GFRA1, sensitivity for CIN2+ was between 43 and $68 \%$; however, these genes showed high specificity between 86 and $94 \%$. In the current Dutch population-based screening program, women with pap2/pap3a (ASCUS/LSIL) scrapings are retested after 6 months with triage testing by hrHPV. Therefore, we also show the results of triage testing by hrHPV and methylation markers in this group (Table 5). Triage testing by hrHPV shows a sensitivity for CIN2+ of $82 \%$ with a specificity of $41 \%$; GATA4, LHX8, and TERT show comparable results.
Different combinations of genes were analyzed to find the methylation marker panel with the highest combined sensitivity and specificity. A sample was considered positive if one of the genes in the combination tested was positive. By adding more than 3 genes in a combination, specificity of the methylation test decreased, with minimal increase in sensitivity. The combinations of genes with the highest combined sensitivity and specificity for CIN2+ were JAM3/ANKRD18CP, C13ORF18/JAM3/ $A N K R D 18 C P$, and JAM3/GFRA1/ANKRD18CP with sensitivities of 72,74 , and $73 \%$, respectively, which are comparable to hrHPV testing (79\%). Specificity of the combinations were 79,76 , and $77 \%$, respectively, which are significantly higher than for hrHPV testing $(42 \%)(p \leq 0.05)$. Table 6 shows that for all other combinations, sensitivities for detecting CIN2+ lesions are between 64 and $80 \%$, with a combined specificity between 58 and $88 \%$. For the detection of CIN3+ only, overall the sensitivity slightly increased (72-85 \%), whereas the specificity decreased (48 and $72 \%)$ (Table 6).

In hrHPV-positive scrapings, the sensitivities and specificities for CIN2+ of the 3 best-performing combinations (JAM3/ANKRD18CP, C13ORF18/JAM3/ANKRD $18 C P$, and JAM3/GFRA1/ANKRD18CP) were comparable (sensitivity 76-77 \%; specificity $81-83 \%$ ) (Table 7) to the population referred with an abnormal Pap smear. The sensitivity to detect CIN3+ of these 3 combinations again slightly increased to $85 \%$, while the specificity decreased 61-64 \% (Table 7).

\section{Discussion}

In this study, we report new CIN2/3-specific methylation markers identified by a genome-wide DNA methylation screening strategy comparing CIN2/3 and normal cervical cells. Diagnostic evaluation in cervical scrapings shows that for 8 newly identified genes, the relative level of methylation increases with the severity of the underlying histological lesion. Combining our newly identified genes with our previously reported panel (C13ORF18, $J A M 3, E P B 41 L 3$, and TERT) [21,22] reveals that for the combinations JAM3/ANKRD18CP, C13ORF18/JAM3/ ANKRD18CP, and JAM3/GFRA1/ANKRD18CP, sensitivities for CIN2+ were between 72 and $74 \%$, which was comparable to the sensitivity for CIN2+ of hrHPV testing $(79 \%)$. Specificities of these new gene panels were between 76 and $79 \%$, which was significantly higher $(p \leq 0.05)$ than the specificity for hrHPV testing (42\%) in a triage setting after a positive Pap smear test result in population-based screening. Furthermore, in hrHPVpositive scrapings, sensitivity and specificity for CIN2+ of these best-performing combinations were comparable to the population referred with an abnormal Pap smear. 
Table 5 Sensitivity and specificity results for CIN2+ and CIN3+ in scrapings of hrHPV-positive women ( $n=152)$. And in scraping of pap2/pap3a (ASCUS/LSIL) patients $(n=124)$

\begin{tabular}{|c|c|c|c|c|}
\hline & Sensitivity CIN2+ & Specificity CIN2+ & Sensitivity CIN3+ & Specificity CIN3+ \\
\hline \multicolumn{5}{|c|}{ Only hrHPV-positive patients $(n=152)$} \\
\hline ZSCAN1 & $94 \%$ & $36 \%$ & $96 \%$ & $23 \%$ \\
\hline ST6GALNAC5 & $92 \%$ & $19 \%$ & $94 \%$ & $15 \%$ \\
\hline ANKRD18CP & $65 \%$ & $86 \%$ & $74 \%$ & $71 \%$ \\
\hline $\mathrm{CDH} 6$ & $72 \%$ & $64 \%$ & $83 \%$ & $57 \%$ \\
\hline GFRA1 & $51 \%$ & $92 \%$ & $64 \%$ & $85 \%$ \\
\hline GATA4 & $85 \%$ & $47 \%$ & $88 \%$ & $33 \%$ \\
\hline KCNIP4 & $98 \%$ & $11 \%$ & $99 \%$ & $7 \%$ \\
\hline LHX8 & $81 \%$ & $53 \%$ & $91 \%$ & $47 \%$ \\
\hline C13ORF18 & $43 \%$ & $94 \%$ & $54 \%$ & $88 \%$ \\
\hline EPB41L3 & $72 \%$ & $78 \%$ & $85 \%$ & $68 \%$ \\
\hline JAM3 & $68 \%$ & $94 \%$ & $80 \%$ & $76 \%$ \\
\hline TERT & $81 \%$ & $47 \%$ & $90 \%$ & $43 \%$ \\
\hline \multicolumn{5}{|c|}{ Only pap2/3a patients $(n=124)$} \\
\hline ZSCAN1 & $90 \%$ & $27 \%$ & $87 \%$ & $20 \%$ \\
\hline ST6GALNAC5 & $90 \%$ & $16 \%$ & $96 \%$ & $15 \%$ \\
\hline ANKRD18CP & $38 \%$ & $82 \%$ & $41 \%$ & $75 \%$ \\
\hline $\mathrm{CDH} 6$ & $58 \%$ & $59 \%$ & $73 \%$ & $56 \%$ \\
\hline GFRA1 & $22 \%$ & $92 \%$ & $32 \%$ & $90 \%$ \\
\hline GATA4 & $78 \%$ & $44 \%$ & $77 \%$ & $35 \%$ \\
\hline KCNIP4 & $98 \%$ & $8 \%$ & $100 \%$ & $6 \%$ \\
\hline$L H X 8$ & $70 \%$ & $49 \%$ & $86 \%$ & $46 \%$ \\
\hline C13ORF18 & $23 \%$ & $95 \%$ & $30 \%$ & $90 \%$ \\
\hline EPB41L3 & $51 \%$ & $78 \%$ & $74 \%$ & $72 \%$ \\
\hline JAM3 & $44 \%$ & $91 \%$ & $57 \%$ & $80 \%$ \\
\hline TERT & $74 \%$ & $48 \%$ & $87 \%$ & $43 \%$ \\
\hline hrHPV & $82 \%$ & $41 \%$ & $82 \%$ & $32 \%$ \\
\hline
\end{tabular}

Due to introduction of primary prevention of cervical cancer through prophylactic vaccination against hrHPV types 16 and 18, involved in $70 \%$ of cervical cancers, the incidence of cervical neoplasia will decrease [14]. Current implementation of HPV vaccination programs in Europe will not have a real impact on the incidence of CIN2/3+ within the next 10-15 years. However, this decline in incidence will most probably impair the diagnostic performance of HPV testing and cytology triage testing even more, resulting in less efficient populationbased screening programs [14]. There is therefore an urgent need to further improve current methodology for cervical cancer screening including new markers that are not associated with HPV.

Our strategy revealed 164 genes, of which the highest ranking 15 genes were validated in different steps. From the 164 identified genes, 10 were described previously in literature (POU4F3, WT1, TBX3, SOX1, COL6A2, ALK,
SOX17, PCDH10, CTNND2, APOBEC2) as being more frequently methylated in CIN2/3 lesions and/or cervical cancer compared to normal cervices, indicating the validity of our approach. Of these 10 genes, POU4F3 was further selected for validation in our approach, although we could not confirm the data already reported [52]. This might be due to another primer design as we used the DMR identified by MethylCap-seq. More CIN2+-specific markers are necessary since literature shows that methylation markers were often tested on CIN3 scrapings only and did not analyze scrapings of CIN2 patients $[19,20,30]$.

In the current Dutch population-based screening program, women with pap2/pap3a (ASCUS/LSIL) scrapings are retested, after 6 months with triage testing by hrHPV. We showed that some single methylation markers had similar sensitivity and specificity for CIN2+ as hrHPV testing. However, combining methylation 
Table 6 Combinations of different methylation markers to create a panel of genes most suited as test in scrapings ranked on highest sensitivity $(n=215)$

\begin{tabular}{|c|c|c|c|c|}
\hline Gene combination & Sensitivity CIN2+ & Specificity CIN2+ & Sensitivity CIN3+ & Specificity CIN3+ \\
\hline JAM3/CDH6 & $80 \%$ & $58 \%$ & $85 \%$ & $48 \%$ \\
\hline ANKRD18CP/CDH6/EPB41L3 & $80 \%$ & $55 \%$ & $87 \%$ & $48 \%$ \\
\hline CDH6/EPB41L3 & $78 \%$ & $57 \%$ & $85 \%$ & $50 \%$ \\
\hline GFRA1/EPB41L3/CDH6 & $78 \%$ & $57 \%$ & $85 \%$ & $50 \%$ \\
\hline ANKRD18CP/CDH6 & $77 \%$ & $57 \%$ & $83 \%$ & $49 \%$ \\
\hline GFRA1/ANKRD18CP/CDH6 & $77 \%$ & $57 \%$ & $83 \%$ & $49 \%$ \\
\hline JAM3/EPB41L3/ANKRD18CP & $76 \%$ & $71 \%$ & $84 \%$ & $60 \%$ \\
\hline C13ORF18/JAM3/ANKRD18CP & $74 \%$ & $76 \%$ & $80 \%$ & $62 \%$ \\
\hline ANKRD18CP/EPB41L3 & $74 \%$ & $74 \%$ & $83 \%$ & $64 \%$ \\
\hline GFRA1/EPB41L3/ANKRD18CP & $74 \%$ & $74 \%$ & $84 \%$ & $64 \%$ \\
\hline C13ORF18/CDH6 & $74 \%$ & $58 \%$ & $80 \%$ & $51 \%$ \\
\hline JAM3/GFRA1/ANKRD18CP & $73 \%$ & $77 \%$ & $80 \%$ & $64 \%$ \\
\hline C13ORF18/JAM3/EPB41L3 & $73 \%$ & $72 \%$ & $83 \%$ & $64 \%$ \\
\hline GFRA1/CDH6 & $73 \%$ & $60 \%$ & $80 \%$ & $53 \%$ \\
\hline JAM3/ANKRD18CP & $72 \%$ & $79 \%$ & $79 \%$ & $65 \%$ \\
\hline JAM3/EPB41L3 & $72 \%$ & $75 \%$ & $83 \%$ & $66 \%$ \\
\hline JAM3/EPB41L3/GFRA1 & $72 \%$ & $76 \%$ & $83 \%$ & $66 \%$ \\
\hline GFRA1/EPB41L3 & $69 \%$ & $79 \%$ & $82 \%$ & $71 \%$ \\
\hline C13ORF18/EPB41L3 & $69 \%$ & $75 \%$ & $81 \%$ & $68 \%$ \\
\hline C13ORF18/JAM3/GFRA1 & $66 \%$ & $82 \%$ & $77 \%$ & $72 \%$ \\
\hline JAM3/GFRA1 & $65 \%$ & $86 \%$ & $76 \%$ & $75 \%$ \\
\hline C13ORF18/ANKRD18CP & $65 \%$ & $79 \%$ & $72 \%$ & $67 \%$ \\
\hline C13ORF18/JAM3 & $64 \%$ & $88 \%$ & $73 \%$ & $76 \%$ \\
\hline GFRA1/ANKRD18CP & $64 \%$ & $81 \%$ & $72 \%$ & $69 \%$ \\
\hline
\end{tabular}

${ }^{\mathrm{a}}$ These gene combinations showed the highest combined sensitivity and specificity

markers might improve the sensitivity but mostly resulting in a decrease of specificity.

Cervical cancer screening will change to primary hrHPV screening in the Netherlands in 2016. Because of the relatively low specificity of the hrHPV test, a triage test is necessary for hrHPV-positive women to prevent unnecessary referral to the gynecologist. Although triage testing with cytology is now mostly advocated, this test has some disadvantages because of its subjectivity and unreliability to test on material collected with selfsampling [31]. Therefore, we analyzed the performance of our methylation markers also in hrHPV-positive scrapings. The combination JAM3/ANKRD18CP, C13OR F18/JAM3/ANKRD18CP, and JAM3/GFRA1/ANKRD18 $C P$ showed in the hrHPV-positive scrapings sensitivities for CIN2+ between 76 and $77 \%$ and specificities between 81 and $83 \%$. These results are better than for other reported triage strategies in literature, such as immunohistochemical staining with p16INK4a and/or KI67 that report sensitivities for detecting CIN2/3 77-87\% with a specificity of $\sim 60 \%$ [32-34] or for HPV 16/18 genotyping which reports sensitivity for CIN $2 / 3$ around $65 \%$ with a specificity of $73 \%$ [35]. Since our methylation panel was tested in a selected patient group that was referred from population-based screening with abnormal cytology, further validation in hrHPV-positive scrapings collected from a large cohort of women from population-based screening should be performed. These kinds of scrapings from real-life cohorts will become available in the Netherlands after 2016 when primary screening has changed to hrHPV testing.

The advantage of methylation marker analysis is that it is an objective test and can be performed on the same material used for hrHPV testing, which makes it also interesting for self-sampled material [36-38]. Different methylation markers already have been tested as a triage test in hrHPV-positive women [19, 21, 30, 39-42]. However, for most of these markers, a cut-off value was set above a certain methylation level in order to obtain high specificity. The advantage of our methylation panel is that no cut-off value is needed. If the PCR product is negative (i.e., no amplification of specific product), the 
Table 7 Combinations of different methylation markers to create a panel of genes most suited as triage test in HPV-positive scrapings ranked on highest sensitivity $(n=152)$

\begin{tabular}{|c|c|c|c|c|}
\hline Gene combination & Sensitivity CIN2+ & Specificity CIN2+ & Sensitivity CIN3+ & Specificity CIN3+ \\
\hline JAM3/CDH6 & $80 \%$ & $64 \%$ & $88 \%$ & $50 \%$ \\
\hline ANKRD18CP/CDH6/EPB41L3 & $79 \%$ & $61 \%$ & $89 \%$ & $51 \%$ \\
\hline CDH6/EPB41L3 & $77 \%$ & $61 \%$ & $88 \%$ & $53 \%$ \\
\hline GFRA1/EPB41L3/CDH6 & $78 \%$ & $61 \%$ & $88 \%$ & $53 \%$ \\
\hline ANKRD18CP/CDH6 & $77 \%$ & $61 \%$ & $85 \%$ & $51 \%$ \\
\hline GFRA1/ANKRD18CP/CDH6 & $77 \%$ & $61 \%$ & $85 \%$ & $51 \%$ \\
\hline JAM3/EPB41L3/ANKRD18CP & $78 \%$ & $72 \%$ & $88 \%$ & $58 \%$ \\
\hline C13ORF18/JAM3/ANKRD18CPa & $77 \%$ & $81 \%$ & $85 \%$ & $61 \%$ \\
\hline ANKRD18CP/EPB41L3 & $75 \%$ & $75 \%$ & $86 \%$ & $63 \%$ \\
\hline GFRA1/EPB41L3/ANKRD18CP & $75 \%$ & $75 \%$ & $86 \%$ & $63 \%$ \\
\hline C13ORF18/CDH6 & $73 \%$ & $61 \%$ & $83 \%$ & $54 \%$ \\
\hline JAM3/GFRA1/ANKRD18CP & $76 \%$ & $81 \%$ & $85 \%$ & $63 \%$ \\
\hline C13ORF18/JAM3/EPB41L3 & $76 \%$ & $72 \%$ & $86 \%$ & $60 \%$ \\
\hline GFRA1/CDH6 & $72 \%$ & $64 \%$ & $83 \%$ & $57 \%$ \\
\hline JAM3/ANKRD18CP & $76 \%$ & $83 \%$ & $85 \%$ & $64 \%$ \\
\hline JAM3/EPB41L3 & $75 \%$ & $75 \%$ & $86 \%$ & $63 \%$ \\
\hline JAM3/EPB41L3/GFRA1 & $75 \%$ & $75 \%$ & $86 \%$ & $63 \%$ \\
\hline GFRA1/EPB41L3 & $72 \%$ & $78 \%$ & $85 \%$ & $68 \%$ \\
\hline C13ORF18/EPB41L3 & $72 \%$ & $75 \%$ & $85 \%$ & $65 \%$ \\
\hline C13ORF18/JAM3/GFRA1 & $70 \%$ & $86 \%$ & $81 \%$ & $71 \%$ \\
\hline JAM3/GFRA1 & $69 \%$ & $89 \%$ & $81 \%$ & $74 \%$ \\
\hline C13ORF18/ANKRD18CP & $68 \%$ & $83 \%$ & $76 \%$ & $67 \%$ \\
\hline C13ORF18/JAM3 & $69 \%$ & $92 \%$ & $80 \%$ & $74 \%$ \\
\hline GFRA1/ANKRD18CP & $67 \%$ & $83 \%$ & $76 \%$ & $68 \%$ \\
\hline
\end{tabular}

${ }^{\mathrm{a}}$ These gene combinations showed the highest combined sensitivity and specificity

samples are called negative and any ratio above zero is called positive. This unique feature of the selected genes allows an objective and easy to interpret test. However, although we focused on the methylation markers for which no cut-off was required, the other identified markers are still of interest for further investigation.

The gene ANKRD18CP (ankyrin repeat domain 18C, pseudogene) is located on chromosome 9 and its function is still unknown. Moreover, methylation of ANKRD18CP was not described before in any type of cancer. The gene CDH6 (Cadherin 6) belongs to the family of cadherins. Cadherins are membrane glycoproteins that mediate homophilic cell-cell adhesion and play critical roles in cell differentiation and morphogenesis. Decreased expression of this gene may be associated with tumor growth and metastasis. It has recently been described as a new transforming growth factor- $\beta$ (TGF- $\beta$ ) target in thyroid tumor patients [43]. The gene GFRA1 (GDNF family receptor alpha 1) plays a key role in the control of neuron survival and differentiation. It has been described as differentially methylated between cancerous and non-cancerous tissue obtained from lung cancer patients based on DNA methylation profiles [44].

The strengths of our current study are (1) the genome-wide approach with MethylCap-seq for specific identification of differential methylation regions between normal cervices and CIN2/3 lesions, (2) the systematic verification and validation of the markers found using carefully revealed cohorts, and (3) the selection of the best-performing markers for diagnostic evaluation in cervical scrapings. The limitation of the current study was that the diagnostic evaluation of the markers could not be performed on women with HPV-positive scrapings with normal cytology, because referral for colposcopy with biopsies of this specific group is presently not allowed by law in the Netherlands. Importantly, it has been shown that approximately $25 \%$ of the CIN2+ cases are hrHPV positive with a subsequent normal cytology $[10,42]$. To study the effect of our results reported in this manuscript is subject of future investigations.

Population-based screening is in transition and methylation markers might be an important component in 
future screening settings. It is important to validate the most interesting markers described in literature in a population-based screening trial. Verification of the results by different groups is important to assure the reproducibility of the methylation analysis. The combination of genes with the highest possible sensitivity and specificity should be evaluated.

\section{Conclusions}

In conclusion, we identified several new CIN2/3-specific methylation markers for detection of cervical neoplasia in cervical scrapings. These newly found markers might be applied as a triage test in hrHPV-positive women from population-based screening.

\section{Methods}

\section{General strategy}

To characterize the DNA methylome of CIN2/3 lesions and to identify new CIN2 or higher (CIN2+) methylation markers, we applied the following strategy (see Fig. 1): First, methylated DNA was enriched using MBD proteins with subsequent paired-end sequencing (MethylCap-seq) on DNA isolated from fresh-frozen macro-dissected epithelial tissue of $18 \mathrm{CIN} 2 / 3$ lesions (6 CIN2 and 12 CIN3), 20 normal cervices, and two pools of leukocyte DNA of healthy volunteers. In order to identify differential methylated regions (DMRs), we retrieved the reads of promoter and exon regions. We selected methylation markers that showed clear-cut differences between the normal and CIN2/3 cervices, while also the leukocyte count had to be low, to prevent false-positive results. Markers were ranked on high specificity (no methylation in the normal cervices) and high sensitivity (methylation in CIN2/3 lesions). For the highest ranking top 15 genes, MSP primers were designed and methylation patterns were verified on the same DNA, which originally was used for MethylCap-seq. This first validation step enabled verification of MethylCap-seq data by correlating MSP band intensity with the number of reads from the MethylCap-seq. In the second validation step, high prevalence of methylation in the CIN2/3 lesions and no methylation in the normal cervices were analyzed by MSP analysis on DNA isolated from a completely independent cohort of patients (cervical cancer $(n=13)$, CIN2/3 lesions $(n=19)$, and normal cervices $(n=17))$. DNA was isolated from macro-dissected formalin-fixed paraffin-embedded (FFPE) epithelial tissue.

Finally, diagnostic evaluation of the newly discovered methylation markers was performed by QMSP on cervical scrapings. First, we tested the methylation ratios of new biomarkers on a large series of randomly selected scrapings from cervical cancer patients $(n=100)$ and a similar age group of healthy controls $(n=89)$. Secondly, the potential of the new methylation markers as a diagnostic tool was evaluated in a large series of scrapings $(n=215)$ of randomly selected patients, referred with an abnormal Pap smear at population-based screening. Histology was used as the reference standard.

\section{Patient samples}

All patients referred to the outpatient clinic of the University Medical Center Groningen (UMCG) with cervical cancer or an abnormal Pap smear at population-based screening are routinely asked to participate in our ongoing "methylation study" which has been approved by the institutional review board (IRB) of the UMCG. Cervical tissue, scrapings, and clinicopathologic data are prospectively collected and stored in our tissue bank. Within our methylation study tissue samples, scrapings and clinicopathologic data from normal cervices are also collected from patients who planned to undergo a hysterectomy for non-malignant reasons. All cervical tissue that was used for the normal control group was judged as histopathologically normal. Patients referred with cervical cancer are staged according to the FIGO criteria with pelvic examination and biopsies under general anesthesia. Cervical scrapings from both groups (cervical cancer staging and benign gynecologic surgery) were collected before surgery under general anesthesia. All patients referred with an abnormal Pap smear at population-based screening underwent an additional Pap smear prior to colposcopy specifically for this study. In this last cohort, women were only eligible when referred with an abnormal smear at population-based screening and not when they were referred to our hospital with complaints. At colposcopy, biopsies and/or large loop excision of the transformation zone (LLETZ) were performed. The tissue samples were scored by an experienced gynecologic pathologist, and the histological classification was used as the reference standard. If no interference with routine diagnostic evaluation was anticipated, specimens from the CIN lesions were retrieved and stored at $-80{ }^{\circ} \mathrm{C}$. Clinicopathologic data were retrieved from patient files and stored in our large anonymous password-protected institutional gynecologic oncology database. All patients gave written informed consent.

For the frozen tissue samples used in the MethylCapseq analysis, the median age of the CIN2/3 patients was 35 years (interquartile range (IQR) 30-39) and for the patients with normal cervices 43 years (IQR 41-44). For the independent cohort of patients with FFPE samples, the median age of the CIN2/3 patients was 37 years (IQR 34-41), for the patients with normal cervices 43 years (IQR 40-44), and for the cervical cancer patients 49 years (IQR 42-54). For the cervical scrapings, the median age of cervical cancer patients was 50 years (IQR 39-64) and for the patients with normal cervices 47 years (IQR 43-53). The stages of cervical cancer 
patients were 1 (1\%) FIGO stage IA1, 31 (31 \%) FIGO stage IB1, 18 (18 \%) FIGO stage IB2, 21 (21 \%) FIGO stage IIA, 17 (17 \%) FIGO stage IIB, 1 (1\%) FIGO stage IIIA, 8 (8\%) FIGO stage IIIB, and 3 (3\%) FIGO stage IV. Histological classifications of the cervical cancer patients were 70 (70 \%) squamous cell carcinoma (SCC), 21 (21\%) adenocarcinoma (AD), 3 (3\%) adenosquamous carcinoma (ASC), and 6 (6\%) undifferentiated carcinoma. The median age of the patients referred with an abnormal Pap smear was 37 years (IQR 32-43). The histological classifications of these patients were 27 without CIN, 38 CIN1, 45 CIN2, 61 CIN3, and $44 \mathrm{miCa}$ (29 SCC, 12 AD, 3 ASC). The Pap smears were classified according to the Papanicolaou system. Table 3 shows, per histological subgroup, the Pap classification (and translation to Bethesda).

From all frozen tissue samples used for MethylCap-seq and the FFPE samples, $10-\mu \mathrm{m}$ tissue sections were cut and macro-dissection was performed to enrich for epithelial cells. Before and after cutting, a hematoxylin and eosin slide was made to check the presence of epithelial cells. Cervical scrapings were collected in 5-ml ice-cold phosphate-buffered saline (PBS $6.4 \quad \mathrm{mM}^{2} \quad \mathrm{NA}_{2} \mathrm{HPO}_{4}$; $1.5 \mathrm{mM} \mathrm{KH}_{2} \mathrm{PO}_{4} ; 0.14 \mathrm{M} \mathrm{NaCl} ; 2.7 \mathrm{mM} \mathrm{KCl}$ ) and kept on ice until further processing. Of these $5-\mathrm{ml}$ cell suspensions, $1 \mathrm{ml}$ was used for cytomorphological assessment. The remaining $4 \mathrm{ml}$ was centrifuged and the cell pellet was suspended in 1-ml TRAP wash buffer and divided in 4 fractions. Two fractions were stored as dry pellet at $-80^{\circ} \mathrm{C}$ for DNA isolation as described previously [21].

\section{DNA isolation}

Tissue slides from FFPE tissue were deparaffinized using $100 \%$ xylene followed by $100 \%$ ethanol [17]. Genomic DNA from fresh-frozen macro-dissected samples and cervical scrapings was isolated by standard overnight $1 \%$ SDS and proteinase K treatment, salt-chloroform extraction, and isopropanol precipitation as described previously [21]. DNA pellets were washed with $70 \%$ ethanol and dissolved in $150 \mu \mathrm{TE}^{-4}(10 \mathrm{mM}$ Tris/HCL; $0.1 \mathrm{mM}$ EDTA, pH 8.0). Genomic DNA was amplified in a multiplex PCR according to the BIOMED-2 protocol, to check the DNA's structural integrity [45]. For the MethylCap-seq samples, DNA quantity was measured using Quant-iT ${ }^{\mathrm{mm}}$ PicoGreen ${ }^{\circ}$ dsDNA Assay Kit according to manufacturer's protocol (Invitrogen, Carlsbad, CA, USA). For cervical scrapings, DNA concentrations and 260/280 ratios were measured using the Nanodrop ND-1000 Spectrophotometer (Thermo Scientific, Waltham, MA, USA). A 260/280 ratio of $>1.8$ was required for all samples.

\section{CpG-methylated island DNA capturing followed by next- generation sequencing (MethylCap-seq)}

Methylated DNA fragments were captured with methylbinding domains using the MethylCap kit according to manufacturer's instructions (Diagenode, Liège, Belgium). The kit consists of the methyl-binding domain (MBD) of human $\mathrm{MeCP} 2$, as a C-terminal fusion with glutathione$\mathrm{S}$-transferase containing an N-terminal His6-tag. Before capturing, DNA samples (500 ng) were sheared to a size range of 300-1000 bps using a Bioruptor ${ }^{\text {rm }}$ UCD-200 (Diagenode, Liège, Belgium) and fragments of 300 bp were isolated. Leukocyte DNA of 4 healthy controls were included in 2 sets of 2 samples. Captured DNA was paired-end-sequenced on the Illumina Genome Analyzer II platform according to protocol (Illumina, San Diego, CA, USA). Results were mapped on the nucleotide sequence using Bowtie software [46], visualized using BioBix' H2G2 browser (http://h2g2.ugent.be/biobix.html) and processed using the human reference genome (NCBI build 37). The paired-end fragments were unique and located within $400 \mathrm{bp}$ of each other [47].

\section{MethylCap-sequencing analysis}

For statistical analysis, reads of promoter $(-2000 \mathrm{bp}$ to $+500 \mathrm{bp}$ of transcription start site) and exon regions were retrieved. In order to identify differences between normal cervices and CIN2/3 lesions, we dichotomized the read data into methylation positive or negative. Samples were considered negative if a sample showed either 0 or 1 read. Samples were considered methylation positive if a sample showed $\geq 3$ reads in order to be more confident that these regions were truly methylated. Subsequently, regions were ranked based on highest specificity and highest sensitivity for CIN2/3. The candidate markers should fulfill the following criteria: (1) low/negative reads in the leukocytes to prevent false-positive results. The region was excluded if both leukocyte samples showed $>1$ read or if 1 leukocyte sample showed $>2$ reads. (2) Markers should be unmethylated (0 or 1 read) in at least $75 \%(15 / 20)$ of the normal cervix group. (3) Markers should be methylated ( $\geq 3$ reads) in at least $28 \%(5 / 18)$ of the CIN2/3 lesion group.

\section{Verification and validation of MethylCap-sequencing data by methylation specific PCR (MSP)}

MSP primers were designed for the highest ranking top 15 genes (16 DMRs). Sodium bisulfite treatment of isolated genomic DNA (1 $\mu \mathrm{g} / \mathrm{sample})$ was performed according to the recommendations of the EZ DNA methylation kit (Zymo, BaseClear, Leiden, the Netherlands). MSP design and analysis was performed using sequences derived from the H2G2 browser. Each reaction was performed in 30- $\mu$ l total reaction volume, containing: $600 \mathrm{nM}$ of each MSP primer, $1.5 \mu \mathrm{l}$ of bisulfite-treated DNA (approximately $15 \mathrm{ng}$ ), standard PCR components (Applied Biosystems), and $0.5 \mathrm{U}$ AmpliTaq Gold DNA polymerase (Applied Biosystems). Condition of the MSP was $10 \mathrm{~min}$ 
hot-start at $95{ }^{\circ} \mathrm{C} ; 95^{\circ} \mathrm{C}$ for $60 \mathrm{~s}, 60^{\circ} \mathrm{C}$ for $60 \mathrm{~s}$, and $72{ }^{\circ} \mathrm{C}$ $60 \mathrm{~s}$ for a total of 40 cycles, with a final elongation step of $7 \mathrm{~min}$ at $72{ }^{\circ} \mathrm{C}$. Leukocyte DNA from healthy women was used as negative control and in vitro methylated (by SsSI enzyme) leukocyte DNA was used as positive control for each MSP.

\section{Quantitative methylation-specific PCR (QMSP)}

QMSP was performed as described previously by our group with an internal (FAM-ZEN/IBFQ)-labeled hybridization probe for quantitative analyses [21]. Primer and probe sequences are available upon request. $\beta$-actin was used as a methylation independent internal reference gene. QMSP reactions were performed in $10 \mu \mathrm{l}$ final volume, containing: $300 \mathrm{nM}$ of forward and reverse primers, $250 \mathrm{nM}$ of hybridization probe, $5 \mu \mathrm{l}$ of 2* QuantiTect Probe PCR Master Mix (Qiagen, Hilden, Germany) and $2.5 \mu \mathrm{l}$ bisulfite modified DNA (approximately $25 \mathrm{ng}$ ). Each sample was analyzed in triplicate by ABI PRISM ${ }^{\bullet} 7900$ HT Sequence Detection System (Applied Biosystems). Negative and positive controls were the same as used for MSP. Standard curve analysis was performed on each plate and by each primer-probe set on serial dilutions of in vitro methylated leukocyte DNA. A DNA sample was considered methylated if at least 2 out of the 3 wells were methylation positive with a $\mathrm{Ct}$ value below 50 and DNA input of at least $225 \mathrm{pg} \beta$-actin. The relative level of methylation of the region of interest was determined by the following calculation: the average quantity of the methylated region of interest divided by the average quantity of the reference $\beta$-actin gene and multiplied by 10,000 [48]. In our analysis, we also included 4 genes previously described by our group (C13ORF18, $J A M 3, E P B 41 L 3$, and TERT) to compare sensitivity and specificity of these known genes with the newly identified methylation markers. QMSP for these markers was performed as previously described [21].

\section{HPV testing}

HrHPV testing was performed using general primermediated PCR (GP5+/6+) as reported previously [48]. For HPV typing as well as detection of the clinical relevant HPV infections, GP5+/6+-positive cases were tested by $\mathrm{COBAS}^{\circ} 4800 \mathrm{HPV}$ test. The COBAS HPV test individually detects HPV types 16 and 18, while at the same time identifying 12 additional hrHPV types [49]. The COBAS HPV test is routinely used in our iso-15189certified laboratory of molecular pathology on scrapings from the national population-based screening program. For the $\mathrm{COBAS}^{\circ} \mathrm{HPV}$ testing in this study, the PCRonly workflow was used, since no liquid-based scrapings in Preservcyt ${ }^{\oplus}$ were available but only already isolated DNA. This workflow was first validated with DNA isolated from clinical samples that were tested previously in the diagnostic routine and this showed comparable results to the liquid-based samples.

\section{Statistical analysis}

Statistical analysis was performed using SPSS software package (SPSS 20, Chicago, IL, USA).

Spearman's rank correlation coefficient was used to compare the MethylCap-seq reads with the MSP band intensity. Categorical methylation data were analyzed using the Pearson $\chi^{2}$ test. Receiver operating characteristic (ROC) curves were generated and the area under the ROC curve (AUC) was used as a measure of test performance. The Mann-Whitney $U$ test and Kruskall-Wallis test was used to determine differences in methylation ratio in 2 groups or more, respectively. The student $t$ test was used to compare positive methylation and age. To compare sensitivity and specificity of the patient group referred with abnormal cytology by DNA methylation markers versus hrHPV, the extended McNemar test, described by Hawass, was executed [50]. $p$ values lower than 0.05 were considered statistically significant.

\section{Additional file}

Additional file 1: Table S1. Identified DMR's with sensitivity and specificity ranked on the sum of both. (XLSX $21 \mathrm{~kb}$ )

\section{Abbreviations}

ANKRD18CP: ankyrin repeat domain 18C, pseudogene; AUC: area under the ROC curve; CDH6: cadherin 6; CIN: cervical intraepithelial neoplasia; CIN2+: CIN2 and higher; DMR: differential methylated region; FFPE: formalin-fixed paraffinembedded; GFRA1: GDNF family receptor alpha 1; hrHPV: high-risk human papillomavirus; HSIL: high-grade CIN; IQR: interquartile range; IRB: institutional review board; LLETZ: large loop excision of the transformation zone; MBD: methyl-binding domain; MeDIP: methyl-DNA immunoprecipitation; MSP: methylation-specific PCR; PBS: phosphate-buffered saline;

QMP: quantitative MSP; ROC: receiver operating characteristic; UMCG: University Medical Center Groningen.

\section{Competing interests}

WvC, AGJvdZ, ES, and GBAW hold patents related to the content of the manuscript. ES is a member of the scientific advisory board of Roche, Hologic, and QCMD and received travel reimbursements from Roche, Abbott, Hologic Inc., and QCMD. WVC is an employee of MDxHealth, Inc., Irvine, CA, USA.

\section{Authors' contributions}

$A B, R W$, and RWVL performed the QMSP experiments. HGK collected all the cervical scrapings and clinical data. $A B, G H d B$, and GBAW performed the statistical analyses. $\mathrm{HH}$ reviewed the histological slides of patients' samples. WvC, TdM, GBAW, and SD performed and analyzed the MethylCap-seq data. $A B, A G J v d Z, E S$, and GBAW conceived and designed the experiments. $A B$, $A G J v d Z, E S$, and GBAW wrote the paper. All authors read and approved the final manuscript.

\section{Acknowledgements}

This project was financed by the Dutch Cancer Society (RUG-NKB2009-4577).

\section{Author details}

${ }^{1}$ Department of Gynecologic Oncology, internal postal code DA13, Cancer Reserch Center Groningen, University of Groningen, University Medical 
Center Groningen, PO box 30.001, 9700 RB Groningen, The Netherlands. 2Department of Epidemiology, Cancer Reserch Center Groningen, University of Groningen, University Medical Center Groningen, Groningen, The Netherlands. ${ }^{3}$ Department of Pathology, Cancer Reserch Center Groningen, University of Groningen, University Medical Center Groningen, Groningen, The Netherlands. ${ }^{4}$ Department of Mathematical Modeling, Statistics and Bioinformatics, Ghent University, Ghent, Belgium.

\section{Received: 19 November 2015 Accepted: 2 March 2016} Published online: 09 March 2016

\section{References}

1. Peto J, Gilham C, Fletcher O, Matthews FE. The cervical cancer epidemic that screening has prevented in the UK. Lancet. 2004;364:249-56.

2. Arbyn M, Raifu AO, Weiderpass E, Bray F, Anttila A. Trends of cervical cancer mortality in the member states of the European Union. Eur J Cancer. 2009; 45:2640-8.

3. Cuzick J, Clavel C, Petry KU, Meijer CJ, Hoyer H, Ratnam S, et al. Overview of the European and North American studies on HPV testing in primary cervical cancer screening. Int J Cancer. 2006;119:1095-101.

4. Mayrand MH, Duarte-Franco E, Rodrigues I, Walter SD, Hanley J, Ferenczy A, et al. Human papillomavirus DNA versus Papanicolaou screening tests for cervical cancer. N Engl J Med. 2007;357:1579-88.

5. Cox JT, Castle PE, Behrens CM, Sharma A, Wright TC, Cuzick J, et al. Comparison of cervical cancer screening strategies incorporating different combinations of cytology, HPV testing, and genotyping for HPV 16/18: results from the ATHENA HPV study. Am J Obstet Gynecol. 2013;208:3.

6. Walboomers JM, Jacobs MV, Manos MM, Bosch FX, Kummer JA, Shah KV, et al. Human papillomavirus is a necessary cause of invasive cervical cancer worldwide. J Pathol. 1999;189:12-9.

7. Ronco G, Dillner J, Elfstrom KM, Tunesi S, Snijders PJ, Arbyn M, et al. Efficacy of HPV-based screening for prevention of invasive cervical cancer: follow-up of four European randomised controlled trials. Lancet. 2014;383:524-32.

8. Ronco G, Giorgi-Rossi P, Carozzi F, Confortini M, Dalla Palma P, Del Mistro A, et al. Efficacy of human papillomavirus testing for the detection of invasive cervical cancers and cervical intraepithelial neoplasia: a randomised controlled trial. Lancet Oncol. 2010;11:249-57.

9. Bulkmans NW, Berkhof J, Rozendaal L, van Kemenade FJ, Boeke AJ, Bulk S, et al. Human papillomavirus DNA testing for the detection of cervical intraepithelial neoplasia grade 3 and cancer: 5-year follow-up of a randomised controlled implementation trial. Lancet. 2007;370:1764-72.

10. Rijkaart DC, Berkhof J, Rozendaal L, van Kemenade FJ, Bulkmans NW, Heideman DA, et al. Human papillomavirus testing for the detection of high-grade cervical intraepithelial neoplasia and cancer: final results of the POBASCAM randomised controlled trial. Lancet Oncol. 2012;13:78-88.

11. Arbyn M, Ronco G, Anttila A, Meijer CJ, Poljak M, Ogilvie G, et al. Evidence regarding human papillomavirus testing in secondary prevention of cervical cancer. Vaccine. 2012;30 Suppl 5:F88-99.

12. Cuzick J, Arbyn M, Sankaranarayanan R, Tsu V, Ronco G, Mayrand MH, et al. Overview of human papillomavirus-based and other novel options for cervical cancer screening in developed and developing countries. Vaccine. 2008;26 Suppl 10:K29-41.

13. Kulasingam SL, Hughes JP, Kiviat NB, Mao C, Weiss NS, Kuypers JM, et al. Evaluation of human papillomavirus testing in primary screening for cervical abnormalities: comparison of sensitivity, specificity, and frequency of referral. JAMA. 2002;288:1749-57

14. Franco EL, Mahmud SM, Tota J, Ferenczy A, Coutlee F. The expected impact of HPV vaccination on the accuracy of cervical cancer screening: the need for a paradigm change. Arch Med Res. 2009;40:478-85.

15. Baylin SB, Ohm JE. Epigenetic gene silencing in cancer-a mechanism for early oncogenic pathway addiction? Nat Rev Cancer. 2006;6:107-16.

16. Steenbergen RD, Snijders PJ, Heideman DA, Meijer CJ. Clinical implications of (epi)genetic changes in HPV-induced cervical precancerous lesions. Nat Rev Cancer. 2014;14:395-405.

17. Yang N, Nijhuis ER, Volders HH, Eijsink JJ, Lendvai A, Zhang B, et al. Gene promoter methylation patterns throughout the process of cervical carcinogenesis. Cell Oncol. 2010;32:131-43.

18. Bierkens M, Hesselink AT, Meijer CJ, Heideman DA, Wisman GB, van der Zee AG, et al. CADM1 and MAL promoter methylation levels in hrHPV-positive cervical scrapes increase proportional to degree and duration of underlying cervical disease. Int J Cancer. 2013;133:1293-9.
19. Hesselink AT, Heideman DA, Steenbergen RD, Coupe VM, Overmeer RM, Rijkaart D, et al. Combined promoter methylation analysis of CADM1 and MAL: an objective triage tool for high-risk human papillomavirus DNApositive women. Clin Cancer Res. 2011;17:2459-65.

20. Lai HC, Lin YW, Huang RL, Chung MT, Wang HC, Liao YP, et al. Quantitative DNA methylation analysis detects cervical intraepithelial neoplasms type 3 and worse. Cancer. 2010;116:4266-74.

21. Eijsink JJ, Lendvai A, Deregowski V, Klip HG, Verpooten G, Dehaspe L, et al. A four-gene methylation marker panel as triage test in high-risk human papillomavirus positive patients. Int J Cancer. 2012;130:1861-9.

22. Yang $\mathrm{N}$, Eijsink JJ, Lendvai A, Volders $\mathrm{HH}$, Klip H, Buikema $\mathrm{HJ}$, et al. Methylation markers for CCNA1 and C13ORF18 are strongly associated with high-grade cervical intraepithelial neoplasia and cervical cancer in cervical scrapings. Cancer Epidemiol Biomarkers Prev. 2009;18:3000-7.

23. Reesink-Peters N, Wisman GB, Jeronimo C, Tokumaru CY, Cohen Y, Dong SM, et al. Detecting cervical cancer by quantitative promoter hypermethylation assay on cervical scrapings: a feasibility study. Mol Cancer Res. 2004;2:289-95.

24. Laird PW. Principles and challenges of genomewide DNA methylation analysis. Nat Rev Genet. 2010;11:191-203.

25. Lendvai A, Johannes F, Grimm C, Eijsink JJ, Wardenaar R, Volders HH, et al. Genome-wide methylation profiling identifies hypermethylated biomarkers in high-grade cervical intraepithelial neoplasia. Epigenetics. 2012;7:1268-78.

26. Lai HC, Lin YW, Huang TH, Yan P, Huang RL, Wang HC, et al. Identification of novel DNA methylation markers in cervical cancer. Int J Cancer. 2008; 123:161-7.

27. Chen YC, Huang RL, Huang YK, Liao YP, Su PH, Wang HC, et al. Methylomics analysis identifies epigenetically silenced genes and implies an activation of beta-catenin signaling in cervical cancer. Int J Cancer. 2014;135:117-27.

28. Serre D, Lee BH, Ting AH. MBD-isolated Genome Sequencing provides a high-throughput and comprehensive survey of DNA methylation in the human genome. Nucleic Acids Res. 2010;38:391-9.

29. Rauch TA, Pfeifer GP. DNA methylation profiling using the methylated-CpG island recovery assay (MIRA). Methods. 2010;52:213-7.

30. Overmeer RM, Louwers JA, Meijer CJ, Van Kemenade FJ, Hesselink AT, Daalmeijer NF, et al. Combined CADM1 and MAL promoter methylation analysis to detect (pre-)malignant cervical lesions in high-risk HPV-positive women. Int J Cancer. 2011:7:6.

31. Gok M, van Kemenade FJ, Heideman DA, Berkhof J, Rozendaal L, Spruyt JW, et al. Experience with high-risk human papillomavirus testing on vaginal brush-based self-samples of non-attendees of the cervical screening program. Int J Cancer. 2012;130:1128-35.

32. Ikenberg $H$, Bergeron C, Schmidt D, Griesser H, Alameda F, Angeloni C, et al. Screening for cervical cancer precursors with p16/Ki-67 dual-stained cytology: results of the PALMS study. J Natl Cancer Inst. 2013;105:1550-7.

33. Carozzi F, Confortini M, Dalla Palma P, Del Mistro A, Gillio-Tos A, De Marco $L$, et al. Use of p16-INK4A overexpression to increase the specificity of human papillomavirus testing: a nested substudy of the NTCC randomised controlled trial. Lancet Oncol. 2008;9:937-45.

34. Carozzi F, Gillio-Tos A, Confortini M, Del Mistro A, Sani C, De Marco L, et al. Risk of high-grade cervical intraepithelial neoplasia during follow-up in HPVpositive women according to baseline p16-INK4A results: a prospective analysis of a nested substudy of the NTCC randomised controlled trial. Lancet Oncol. 2013;14:168-76.

35. Rijkaart DC, Berkhof J, van Kemenade FJ, Coupe VM, Hesselink AT, Rozendaal $L$, et al. Evaluation of 14 triage strategies for HPV DNA-positive women in population-based cervical screening. Int J Cancer. 2012;130:602-10.

36. Eijsink JJ, Yang $\mathrm{N}$, Lendvai A, Klip HG, Volders HH, Buikema HJ, et al. Detection of cervical neoplasia by DNA methylation analysis in cervicovaginal lavages, a feasibility study. Gynecol Oncol. 2011;120:280-3.

37. Verhoef VM, Dijkstra MG, Bosgraaf RP, Hesselink AT, Melchers WJ, Bekkers RL, et al. A second generation cervico-vaginal lavage device shows similar performance as its preceding version with respect to DNA yield and HPV DNA results. BMC Womens Health. 2013;13:21

38. Boers A, Bosgraaf RP, van Leeuwen RW, Schuuring E, Heideman DA, Massuger LF, et al. DNA methylation analysis in self-sampled brush material as a triage test in hrHPV-positive women. Br J Cancer. 2014;111:1095-101.

39. Brentnall AR, Vasiljevic N, Scibior-Bentkowska D, Cadman L, Austin J, Szarewski A, et al. A DNA methylation classifier of cervical precancer based on human papillomavirus and human genes. Int J Cancer. 2014;135: 1425-32. 
40. Vasiljevic N, Scibior-Bentkowska D, Brentnall AR, Cuzick J, Lorincz AT. Credentialing of DNA methylation assays for human genes as diagnostic biomarkers of cervical intraepithelial neoplasia in high-risk HPV positive women. Gynecol Oncol. 2014;132:709-14.

41. Hansel A, Steinbach D, Greinke C, Schmitz M, Eiselt J, Scheungraber C, et al. A promising DNA methylation signature for the triage of high-risk human papillomavirus DNA-positive women. PLoS One. 2014;9:3.

42. Verhoef VM, Bosgraaf RP, van Kemenade FJ, Rozendaal L, Heideman DA, Hesselink AT, et al. Triage by methylation-marker testing versus cytology in women who test HPV-positive on self-collected cervicovaginal specimens (PROHTECT-3): a randomised controlled non-inferiority trial. Lancet Oncol. 2014;15:315-22.

43. Sancisi V, Gandolfi G, Ragazzi M, Nicoli D, Tamagnini I, Piana S, et al. Cadherin 6 is a new RUNX2 target in TGF-beta signalling pathway. PLoS One. 2013;8:9.

44. Selamat SA, Chung BS, Girard L, Zhang W, Zhang Y, Campan M, et al. Genome-scale analysis of DNA methylation in lung adenocarcinoma and integration with mRNA expression. Genome Res. 2012;22:1197-211.

45. van Dongen JJ, Langerak AW, Bruggemann M, Evans PA, Hummel M, Lavender FL, et al. Design and standardization of PCR primers and protocols for detection of clonal immunoglobulin and T-cell receptor gene recombinations in suspect lymphoproliferations: report of the BIOMED-2 Concerted Action BMH4-CT98-3936. Leukemia. 2003:17:2257-317.

46. Langmead B, Trapnell C, Pop M, Salzberg SL. Ultrafast and memory-efficient alignment of short DNA sequences to the human genome. Genome Biol. 2009;10:3.

47. De Meyer T, Mampaey E, Vlemmix M, Denil S, Trooskens G, Renard JP, et al. Quality evaluation of methyl binding domain based kits for enrichment DNA-methylation sequencing. PLoS One. 2013;8:3.

48. Wisman GB, Nijhuis ER, Hoque MO, Reesink-Peters N, Koning AJ, Volders HH, et al. Assessment of gene promoter hypermethylation for detection of cervical neoplasia. Int J Cancer. 2006;1 19:1908-14.

49. Cui M, Chan N, Liu M, Thai K, Malaczynska J, Singh I, et al. Clinical performance of Roche Cobas 4800 HPV Test. J Clin Microbiol. 2014;52:2210-1.

50. Hawass NE. Comparing the sensitivities and specificities of two diagnostic procedures performed on the same group of patients. Br J Radiol. 1997;70; 360-6.

51. Arbyn M, Bergeron C, Klinkhamer P, Martin-Hirsch P, Siebers AG, Bulten J. Liquid compared with conventional cervical cytology: a systematic review and meta-analysis. Obstet Gynecol. 2008;111:167-77.

52. Pun PB, Liao YP, Su PH, Wang HC, Chen YC, Hsu YW, Huang RL, Chang CC, Lai HC. Triage of high-risk human papillomavirus-positive women by methylated POU4F3. Clin Epigenetics. 2015;7:85. 015-0122-0.

\section{Submit your next manuscript to BioMed Central and we will help you at every step:}

- We accept pre-submission inquiries

- Our selector tool helps you to find the most relevant journal

- We provide round the clock customer support

- Convenient online submission

- Thorough peer review

- Inclusion in PubMed and all major indexing services

- Maximum visibility for your research

Submit your manuscript at www.biomedcentral.com/submit

C Biomed Central 